\title{
Alternative Breed of Three-Phase Four-Wire Shunt Compensators based on Cascaded Transformer with Single Dc-link
}

\author{
Gregory A. de Almeida Carlos ${ }^{1,2}$, Cursino B. Jacobina ${ }^{2,3}$, and Euzeli C. dos Santos Jr. ${ }^{4}$ \\ ${ }^{1}$ Department of Control and Industrial Process - Federal Institute of Alagoas (IFAL) \\ Palmeira dos Índios, AL 57601-220 - Brazil \\ ${ }^{2}$ Post-Graduate Program in Electrical Engineering - PPgEE - Copele \\ Campina Grande, PB 58429-900 - Brazil \\ ${ }^{3}$ Department of Electrical Engineering - Federal University of Campina Grande (UFCG) \\ Campina Grande, PB 58429-900 - Brazil \\ ${ }^{4}$ Department of Electrical and Computer Engineering - Indiana University - Purdue University (IUPUI) \\ Indianapolis, IN 46202 - USA
}

\begin{abstract}
This paper introduces a new breed of four-wire (4W) multilevel shunt compensator to deal with either harmonic or reactive power compensation. The converter configurations are generalized for $\mathrm{K}$-stages and the main benefits of proposed topologies lie on $i$ ) multilevel waveforms generation, $i i$ ) single dclink unit and $\mathrm{iii}$ ) modular characteristic. The configurations are based on cascaded transformers along with three-phase-bridge (TPB) converters. These converters are directly connected to the transformer primary side. A suitable PWM strategy combined with an appropriate transformer turns ratio guarantees the desirable multilevel output waveforms. The modularity feature provides simple maintenance and makes the proposed shunt active power filters (SAPFs) an attractive solution in comparison with conventional configurations. The configuration model and overall control are addressed, as well. Simulation and experimental results are presented for theoretical validation.
\end{abstract}

\section{INTRODUCTION}

The intensive use of non-linear loads have been reported as one of those responsible for decreasing the power quality of electrical power systems [1]. In distribution power systems, this issue becomes even more evident [2], [3]. Non-linear loads and unbalanced loads affect directly the grid by means of the harmonic currents injection and an increase of the reactive power amount, leading to a grid system with low efficiency and poor power factor [4]. Specially in three-phase four wire $(4 \mathrm{~W})$ systems, unbalanced loads will cause excessive currents at neutral conductors which speeds up the equipment degradation [3], [5]. In this way, some custom power companies/industries (e.g., ABB, Siemens, Fuji, Westinghouse, etc) started the development of the so-called active power filters (APFs) [1], [3], [6] to compensate for the aforementioned issues. APFs subdivide into three types: i) series APFs, ii) shunt APFs (SAPFs) and universal APFs. In this paper, the second type (i.e., SAPFs) is focused and applied for three-phase four-wire (4W) systems, see Fig. 1(a). Notice that it is mainly composed by a voltage source converter (VSC) isolated from the power system by an isolation transformers arrangement.
The higher the power-level application (from mediumvoltage to high-voltage), such as distribution voltage levels, the lower conventional two-level (2L) based VSC are used [7]. Hence, medium/high-voltage SAPF configurations experience their VSC based on a multilevel converter due to its costbenefit in front of a $2 \mathrm{~L}$ converter [8], [9]. In this way, some multilevel SAPFs applied in $4 \mathrm{~W}$ systems have been studied and documented in technical literature [8], [10], [11]. However, some of them have drawbacks associated to the high number of dc-link capacitors that leads to an increase in control complexity, imbalance dc-link voltages problems and reduced system reliability. For example, we can highlight VSC based on neutral point-clamped (NPC) [7] or cascaded flying capacitors [10]. In addition, the lifetime of dc-link capacitors stands out as one of the most important issues in terms of failure rate in field operation of power-electronics based systems [12]-[14]. Then, failure probability and harmonic pollution would decrease if a SAPF with single dc-link unit is combined with multilevel features. An alternative way to match these features was achieved in three-wire systems by coupling cascading transformers with H-bridge converters [15].

This paper presents a new breed of $4 \mathrm{~W}$ multilevel shunt compensators generalized for K-stages with a single dc-link unit. Such configurations are based on cascaded transformers coupled with three-phase-bridge (TPB) converters. These converters are connected directly at the transformer primary side. The proposed configurations differ from each other according the addition of a fourth leg to each stage. A suitable PWM strategy combined with transformer turn ratios provides multilevel output waveforms. Modularity and simple maintenance makes proposed SAPF an attractive solution in comparison with conventional configurations. Model and overall control are addressed. Simulation and experimental results are presented as well.

This is the author's manuscript of the article published in final edited form as:

Carlos, G. A. de A., Jacobina, C. B., \& Santos, E. C. dos. (2017). Alternative breed of three-phase four-wire shunt compensators based on cascaded transformer with single dc-link. In 2017 IEEE Applied Power Electronics Conference and Exposition (APEC) 


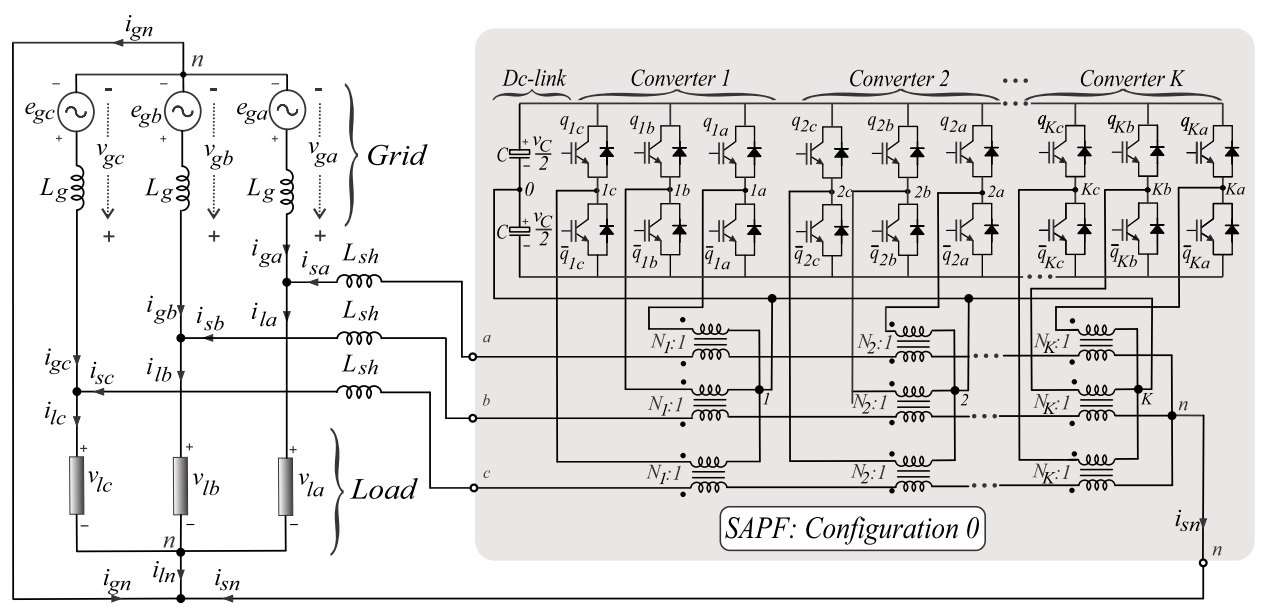

(a)

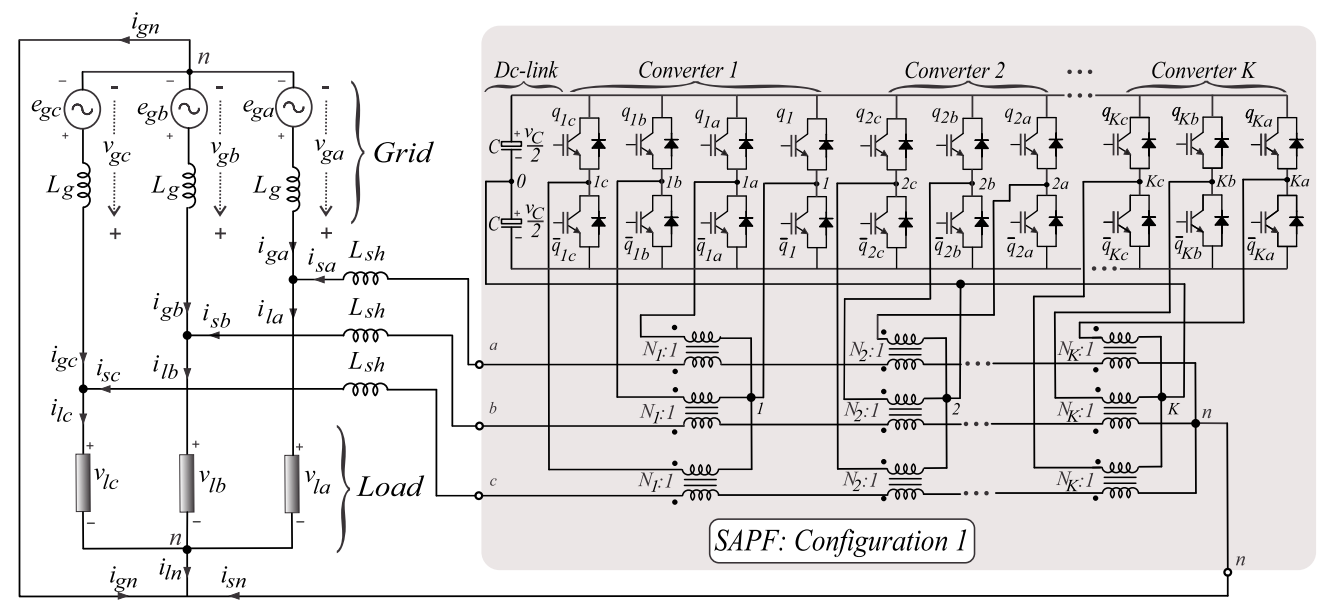

(b)

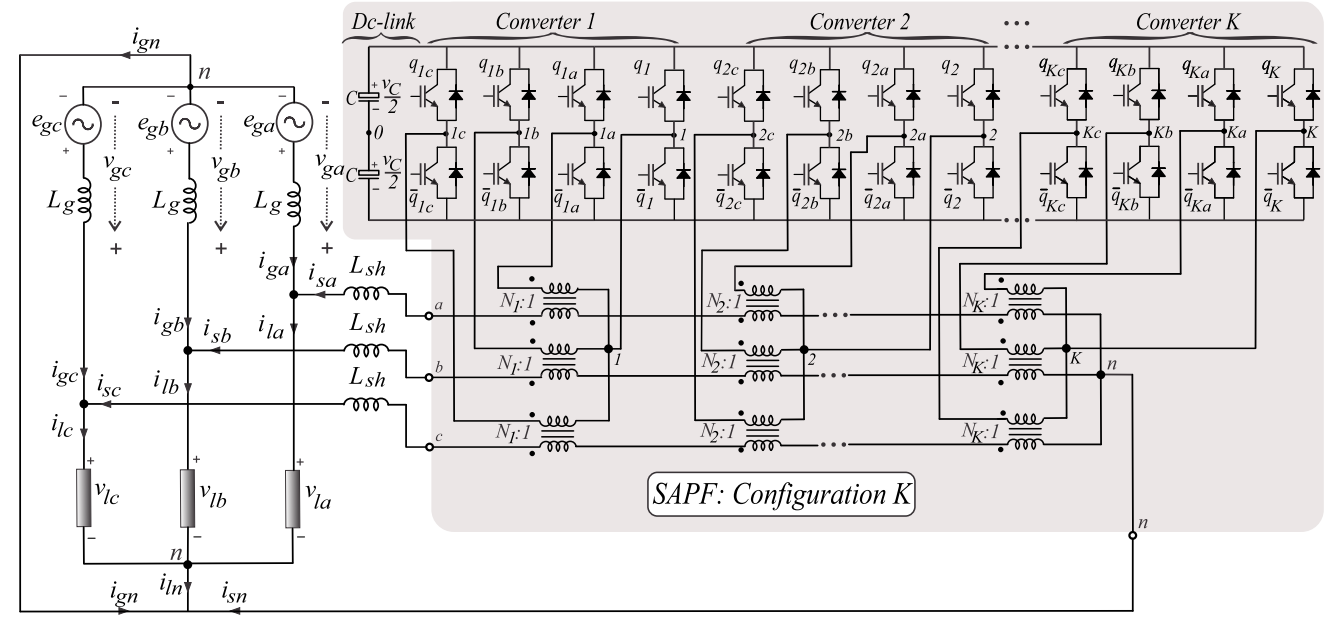

(c)

Fig. 1. Set of proposed shunt active power filter (SAPF) topologies. (a) Configuration 0. (b) Configuration 1. (c) Configuration $K$. 


\section{PROPOSED SAPFS AND THEIR MODELS}

The proposed configurations depend on the number of the fourth-leg connected to the neutral point of the isolation transformers (i.e., 1, 2, 3,.., K). The configurations are defined according to the number of fourth-leg in each TPB $\left(\alpha_{n}\right)$. Then, it ranges from the lowest (i.e., configuration 0: without any fourth-leg $\Rightarrow \alpha_{n}=0$ ) to the generalized case with $K$ TPB with four legs (configuration $K$ : with all stages having a fourth-leg $\left.\Rightarrow \alpha_{n}=K\right)$. A set of the proposed configurations is presented in Fig. 1. The first topology (named as configuration 0), see Fig. 1(a), has the lowest number of power switches. On the other hand, it has limitation with the neutral current control $\left(i_{s n}\right)$ because there is not a fourth-leg at none TPB [4]. In addition, it suffers the same problems as for conventional split-capacitor (e.g., expensive and large value capacitors, extra auxiliary controller to regulate dclink balancing) [4], [16]. However, this characteristic can be improved by adding an additional fourth-leg at each stage resulting in other configurations, see Figs. 1(b) and 1(c). For example, Configuration 1, has only one fourth-leg connected to the neutral point of isolation transformer at the stage number 1. Configuration $K$, see Fig. 1(c), has an additional fourth-leg at all TPBs. This last configuration is considered as the most attractive and studied in details in this paper. Table I gives an overall idea of the topologies that belong to the alternative breed SAPF studied in this paper.

TABLE I

PROPOSED CONFIGURATIONS DESCRIPTION.

\begin{tabular}{c|c|c}
\hline Topology & Number of 4th-leg & 4th-leg Stage-Connection \\
\hline Configuration 0 & 0 & None \\
\hline Configuration 1 & 1 & $1 / 2 / 3 / \ldots / \mathrm{K}$ \\
\hline \multirow{2}{*}{ Configuration 2} & 2 & $\{1,2\} /\{1,3\} / \ldots /\{1, \mathrm{~K}\}$ \\
& 2 & $\{2,3\} /\{2,4\} / \ldots /\{2, \mathrm{~K}\}$ \\
& 2 & $\{1, \mathrm{~K}-1\} /\{2, \mathrm{~K}-2\} / \ldots /\{\mathrm{K}-1, \mathrm{~K}\}$ \\
\hline$\vdots$ & $\vdots$ & $\vdots$ \\
\hline Configuration $\mathrm{K}$ & $\mathrm{K}$ & $1,2, \ldots, \mathrm{K}$ \\
\hline
\end{tabular}

To improve the readability, the topologies can be considered by means of their ideal equivalent circuits. For example, the equivalent ideal circuit of configuration $K$ can be observed in Fig. 2. Since the topologies differ from each other by the number of fourth-leg connections, only the model for configuration $K$ is described in details in this paper. The model for the others configurations can be achieved by particular equations from the configuration $K$ model.

The TPB converter legs are represented by $K$ switchpair per phase (i.e., $q_{1 j}-\bar{q}_{1 j}, \ldots, q_{K j}-\bar{q}_{K j}$ ) where subscript $j$ corresponds to each phase (e.g, $j=a, b, c)$. A fourth-leg switch-pair for each stage is represented by $q_{10^{-}} \bar{q}_{10}, \ldots, q_{K 0^{-}}$ $\bar{q}_{K 0}$. Note that switches $q$ and $\bar{q}$ are complementary to each other, such that $q=1$ means a closed switch while $q=0$ an open one.

The converter pole voltages for each phase $\left(v_{k j 0}\right)$ and for the fourth-leg $\left(v_{k 0}\right)$, can be expressed as

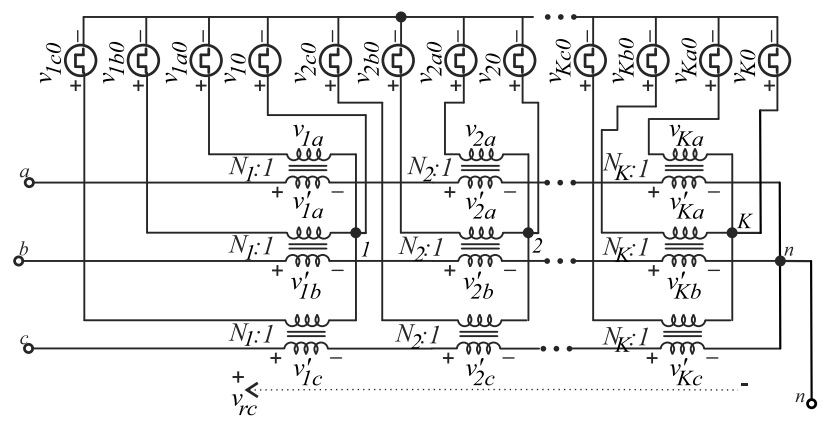

Fig. 2. Ideal equivalent circuit for proposed SAPFs (Configuration $K$ ).

$$
\begin{aligned}
v_{k j 0} & =\left(2 q_{k j}-1\right) \frac{v_{C}}{2} \\
v_{k 0} & =\left(2 q_{k}-1\right) \frac{v_{C}}{2} ;
\end{aligned}
$$

where $k$ is related to each stage (i.e., $k=1,2,3, \ldots, K)$ and $v_{C}$ is the dc-link voltage.

A per-phase circuit simplification for configuration $K$ is shown in Fig. 3. Such a configuration presents its voltages at the primary side of the transformers for each phase as

$$
\begin{gathered}
v_{k a}=v_{k a 0}-v_{k 0} \\
v_{k b}=v_{k b 0}-v_{k 0} \\
v_{k c}=v_{k c 0}-v_{k 0} .
\end{gathered}
$$

The general converter model for proposed SAPF is quite similar to that one presented in a previous work for threewire system [17] with the remark that the neutral connections are the same in this work (i.e., load neutral = grid neutral = transformer secondary neutral). Then, the following equation for SAPF (configuration $K$ ) can be written as

$$
\begin{aligned}
& v_{r j}=l_{s h} \frac{d i_{s j}}{d t}+r_{s h} i_{s j}-l_{g} \frac{d i_{g j}}{d t}-r_{g} i_{g j}+e_{g j} \\
& v_{r j}=v_{1 j}^{\prime}+v_{2 j}^{\prime}+\ldots+v_{K j}^{\prime}
\end{aligned}
$$

where $v_{r j}$ are the resultant output converter voltages related to the secondary voltages of the scaled transformers. $v_{1 j}^{\prime}=$ $N_{1}\left(v_{1 j 0}-v_{10}\right), \ldots, v_{K j}^{\prime}=N_{K}\left(v_{K j 0}-v_{K 0}\right)$ in which $N_{1}$, $\ldots, N_{K}$ are the transformer turns ratios associated with stage converters $1,2, \ldots, K$, respectively.

One of the goals in this work is to verify the quality of the converter voltages generation capability. Hence, it will be considered a perfect isolation from primary to secondary side of the transformers (i.e., ideal transformers). In this way, the output voltages $\left(v_{r j}\right)$ of the resultant converter can be expressed as

$$
\begin{aligned}
v_{r j} & =v_{r j}^{\prime}-v_{r 0} \\
v_{r j}^{\prime} & =N_{1} v_{1 j 0}+N_{2} v_{2 j 0}+\ldots+N_{K} v_{K j 0} \\
v_{r 0} & =N_{1} v_{10}+N_{2} v_{20}+\ldots+N_{K} v_{K 0} .
\end{aligned}
$$

From Fig. 3 it can be seen that the voltages $v_{r j}$ can have a maximized number of levels if the voltages $v_{r j}^{\prime}$ are generated with a suitable PWM strategy combined with transformer turn ratios $\left(N_{1}, \ldots, N_{K}\right)$, as observed in Fig. 4 . The voltage $v_{r 0}$ is responsible to compensate for the major part of neutral 

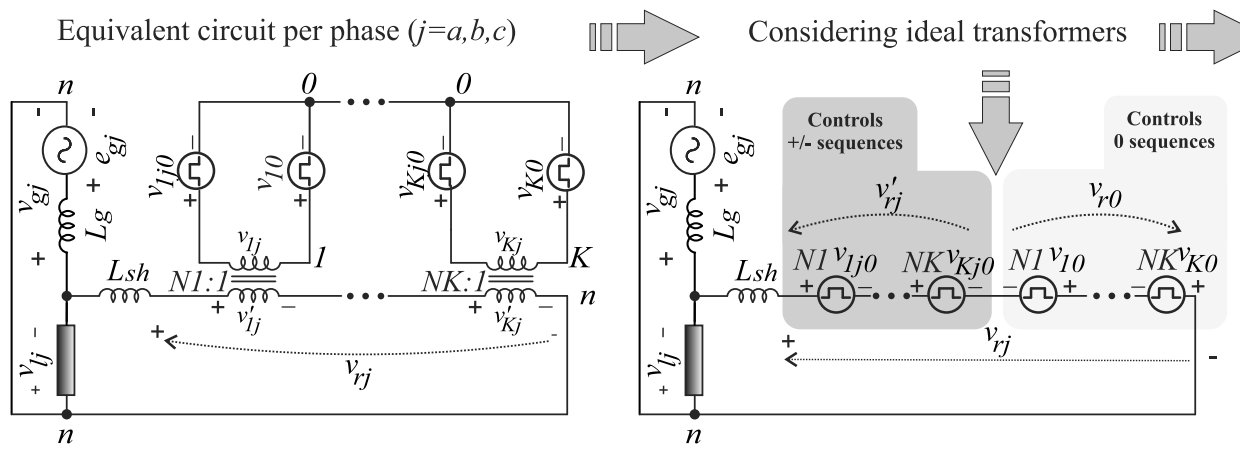
Simplified Circuit

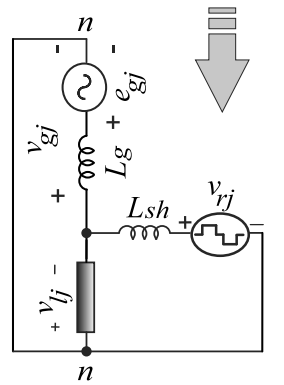

Fig. 3. Simplified circuit per-phase for SAPFs considered with Configuration $K$.

currents $\left(i_{g n}, i_{s n}\right.$ and $\left.i_{l n}\right)$, since they are controlled by means of the added fourth-leg. Such a leg is added in each converter independently of phases $j=a, b, c$. However, for configuration 0 this feature is lost and the neutral grid current is controlled only via the voltages associated with each phase leg.

$$
\begin{aligned}
& -\frac{2-1}{2}-\frac{2-3}{2} v_{C} \ldots-\frac{3}{2} v_{C}-\frac{1}{2} v_{C} \quad \frac{1}{2} v_{C} \quad \frac{3}{2} v_{C} \ldots \frac{2-3}{2} v_{C} \quad \frac{2-1}{2} v_{C}
\end{aligned}
$$

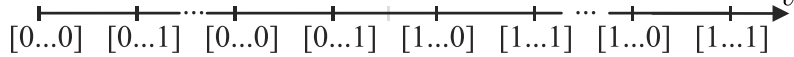

$$
\begin{aligned}
& q_{K \lambda}=0 \quad q_{K \lambda}=0 \quad q_{K \lambda}=0 \quad q_{K \lambda}=0 \quad q_{K \lambda}=1 \quad q_{K \lambda}=1 \quad q_{K \lambda}=1 \quad q_{K \lambda}=1 \\
& q_{1 \lambda}=0 \quad q_{1 \lambda}=1 \quad q_{1 \lambda}=0 \quad q_{1 \lambda}=1 \quad q_{1 \lambda}=0 \quad q_{1 \lambda}=1 \quad q_{1 \lambda}=0 \quad q_{1 \lambda}=1
\end{aligned}
$$

Fig. 4. Example of of generalized 1-D PWM region for voltages $v_{r \lambda}^{\prime *}$ in which $N_{1}=1, N_{2}=2, \ldots, N_{K}=2^{(K-1)}$. Subscript $\lambda$ corresponds to phases $j=a, b, c$ and zero sequence voltages denoted by $r 0$.

\section{PWM STRATEGY}

The pulse width modulation (PWM) technique used in this work is based on level-shifted-carrier-based PWM (LSPWM) associated with the one-dimension (1D) region control approach. 1D control approach has been used for other applications as observed in [18], [19]. The main feature of this approach is that a simpler algorithm calculation can be obtained if compared to others techniques such as space-vector PWM (SVPWM) [4], [20].

The calculation takes into consideration references for the resultant output voltages $\left(v_{r j}^{*^{\prime}}\right)$. The PWM strategy is presented in details for configuration $K$. However, it should be noted that the PWM for the other configurations are particular cases of the one used for configuration $K$.

The references $v_{r j}^{*^{\prime \prime}}$ for the resultant converter are provided by the output signals of a controller such that the references $v_{r j}^{*^{\prime}}$ are given by

$$
\begin{aligned}
v_{r j}^{*^{\prime}} & =v_{r j}^{*^{\prime \prime}}+v_{r 0}^{*} \\
v_{r 0}^{*^{\prime}} & =v_{r 0}^{*}
\end{aligned}
$$

with $v_{r j}^{*^{\prime}}=v_{1 j}^{*^{\prime}}+v_{2 j}^{*^{\prime}}+\ldots+v_{K j}^{*^{\prime}}$. The reference $v_{r 0}^{*}$ is a degree of freedom from the additional fourth-leg. $v_{r 0}^{*^{\prime}}$ is the reference for the resultant fourth-leg.
The reference voltage for $v_{r 0}^{*}$ is calculated as

$$
v_{r 0}^{*}=\mu_{r 0}^{*} v_{r 0 \max }^{*}+\left(1-\mu_{r 0}^{*}\right) v_{r 0 \min }^{*}
$$

where $0 \leq \mu_{r 0}^{*} \leq 1$ and

$$
\begin{aligned}
& v_{r 0 \min }^{*}=-0.5 v_{C}^{*}\left(N_{1}+\ldots+N_{K}\right)-\min \left\{v_{r j}^{*^{\prime \prime}}, 0\right\} \\
& v_{r 0 \max }^{*}=0.5 v_{C}^{*}\left(N_{1}+\ldots+N_{K}\right)-\max \left\{v_{r j}^{*^{\prime \prime}}, 0\right\} .
\end{aligned}
$$

Once voltages $v_{r j}^{*^{\prime \prime}}$ (i.e., $v_{r a}^{*^{\prime \prime}}, v_{r b}^{*^{\prime \prime}}$ and $v_{r c}^{*^{\prime \prime}}$ ) are given from the controller, the algorithm to calculate $v_{r j}^{* \prime}$ is summarized in following steps:

1) Calculate the $v_{r 0 \min }^{*}$ and $v_{r 0 \max }^{*}$ values according to (14) and (15), respectively;

2) Choose $\mu_{r 0}^{*}$ and determine $v_{r 0}^{*}$ from (13);

3) Calculate $v_{r j}^{*^{\prime}}$ and $v_{r 0}^{*^{\prime}}$ from (12).

For transformer turns ratio fixed as $N_{1}=1, N_{2}=2, \ldots$, $N_{K}=2^{(K-1)}$, the reference voltages $v_{r \lambda}^{*^{\prime}}$ are compared with $2^{K}-1$ triangular waveforms, which are level-shifted carriers $\left(v_{t 1}-v_{t 2^{K}-1}\right)$ placed according to the levels that the resultant converter can offer, see Fig. 4. It should be noted that for equal transformer turns ratios (e.g., $N_{1}=N_{2}=\ldots=N_{K}=1$ ), lower number of levels will be presented at $v_{r \lambda}^{*^{\prime}}$ but with more redundancy switching states. As a consequence the number of triangular waveforms is reduced for $K$ providing $K+1$ levels at the output voltage.

The result of this comparison gives the switching states $\left(q_{1 j}\right.$, $\ldots, q_{K j}$ ) that are imposed for each converter. The implementation for the resultant additional fourth-leg $v_{r 0}^{*}$ is done similarly. A summarized PWM block diagram highlighting each step is presented in Fig. 5.

\section{CONTROL STRATEGY}

Fig. 6 presents the control block diagram of the system considered for configuration $K$. Notice that the control block diagram for the other configurations are particular cases of the one presented in Fig. 6. The dc-link capacitor voltage $v_{C}$ is controlled by means of the controller $R_{C}$, whose output gives the reference amplitude grid current $I_{g}^{*}$ of the system. The instantaneous reference grid currents for each phase (i.e., $i_{g j}$ ) are obtained by synchronizing their phase with grid voltages $e_{g j}$, indicated by the block $S_{i n}$. The synchronization is done via a phase-locked-loop (PLL) based 


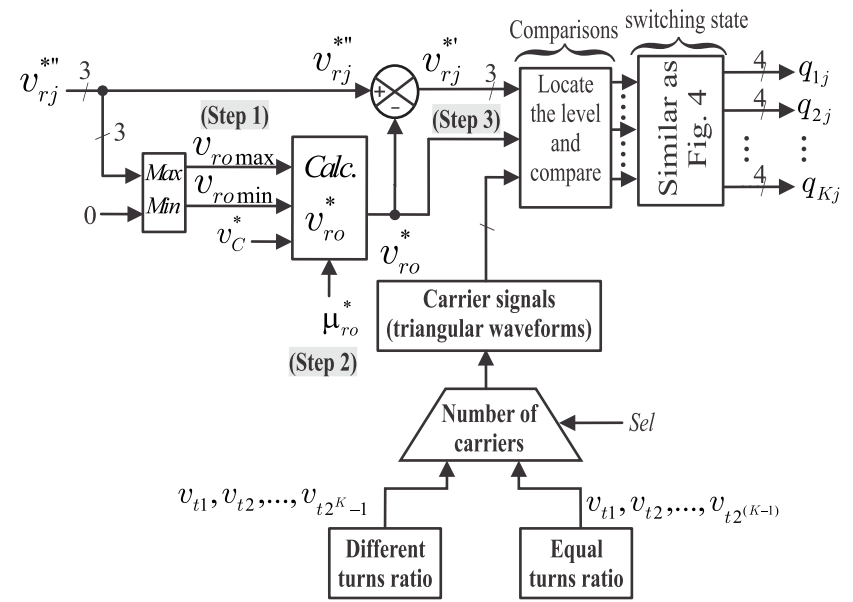

Fig. 5. Summarized and generalized PWM block diagram for configuration $\mathrm{K}$.

on a ficticious power as detailed in [21]. The controllers $R i_{j}$ define the reference voltages $v_{r j}^{*^{\prime \prime}}$. From the reference voltages, the PWM strategy defines the state of the power switches as described in Fig. 5. The $R_{C}$ controlled is implemented as a conventional PI (proportional-integral) controller whereas the current controllers $R i_{j}$ are resonant controllers [22].

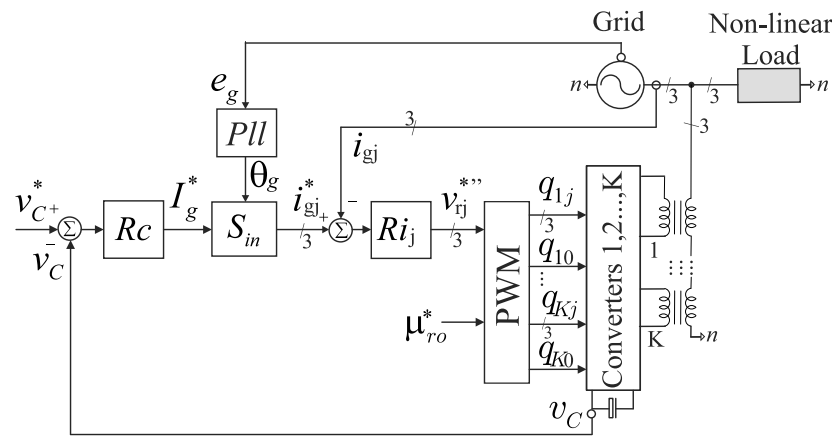

Fig. 6. Block diagram of overall control strategy of proposed SAPF considered for configuration $K$.

\section{SIMULATION RESULTS}

Some simulation results were obtained by means of PSIM $v 9.0$. The dynamic operation of the system has been tested. In this way, the system currents and the dc-link voltage regulation were observed. Fig. 7 shows a set of results obtained for configuration $K$ operating with $N_{1}=N_{2}=1$ under a load transient applied at $t=0.5 \mathrm{~s}$. It can be seen that the SAPF configuration has operated satisfactorily.

Output voltage waveforms were observed and quantified by means of the Weighted Total Harmonic Distortion (WTHD). Fig. 8 shows a set of simulation results trough PSIM $v 9.0$ for conventional $\mathrm{HB}$, and configuration $K$. Proposed one is operating with 2 stages (i.e., $K=2$ ) with transformer turns ratios equal to to $N_{1}=N_{2}=1$ [Fig. 8(b)] or with $N_{1}=1$ and $N_{2}=2$ [Fig. 8(c)]. Such outcomes show profile off the resultant output voltages(i.e., $v_{r j}$ ) with PWM implementation described previously. In this case the SAPF compensates only

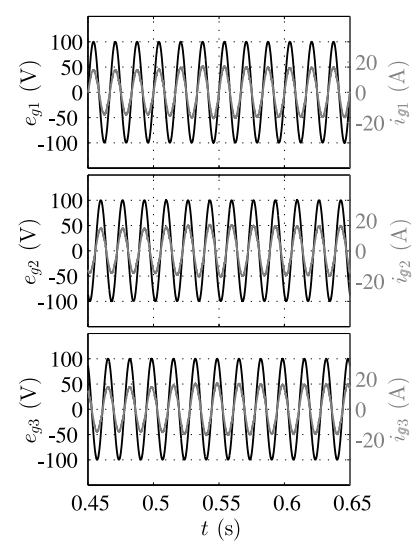

(a)

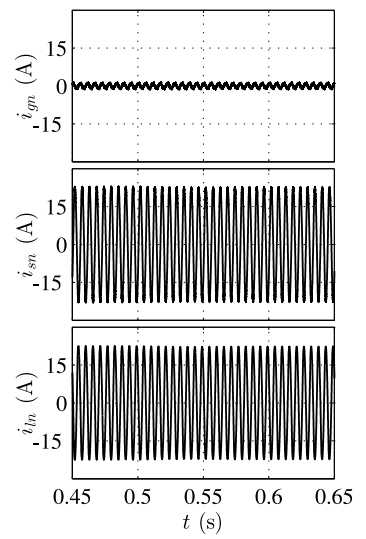

(c)

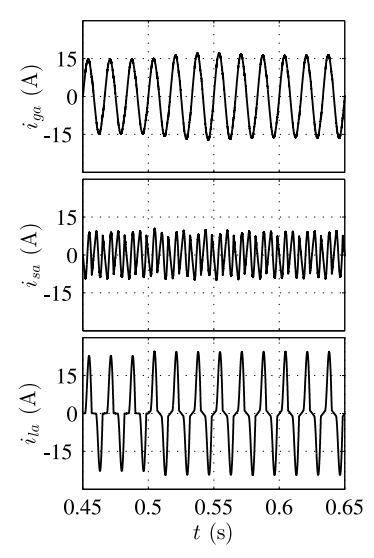

(b)

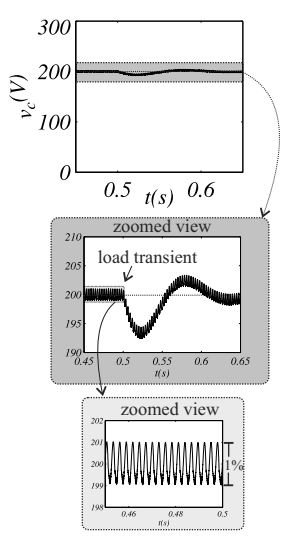

(d)
Fig. 7. Set of simulation results for configuration $\mathrm{K}$ operating with: 2 stages (i.e., $K=2$ ), equal transformer turns ratio (i.e., $N_{1}=N_{2}=1$ ) and a load transient at $t=0.5 \mathrm{~s}$. (a) Grid voltages and currents. (b) System currents for one phase. (c) Neutral currents. (d) Dc-link voltage with $v_{c}^{*}=200 \mathrm{~V}$.

for reactive power. It can be seen that the result presented in Figs. 8(b) and (c) provides a better waveform quality than the one obtained with conventional SAPF with transformers coupled with H-Bridge cells with 1-stage [15], as observed in Fig. 8(a). In this case, proposed configuration $K$ will have $2 K$ more power switches but with conditions to provide lower switching losses due to the reduced WTHD at $v_{r j}$ that reflects in the THD of $i_{g j}$.

\section{EXPERIMENTAL RESULTS}

Some experimental tests were performed by considering a downscaled experimental platform. Such a platform includes power switches as IGBTs from Semikron (SKM50GB123D) with drivers (SKHI23). The drivers are linked to the control strategy via a digital signal processor (DSP) TMS320F28335. The DSP sends the gating signals trough optical fiber cables. The dc-link voltage and grid currents sensors are connected to the analog-digital inputs by means of plug-in boards with 


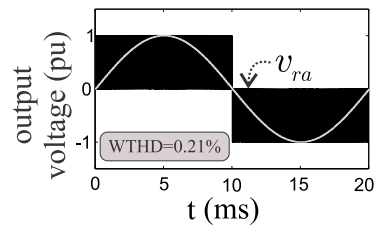

(a)

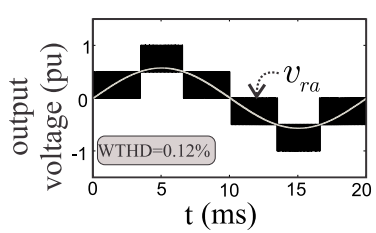

(b)

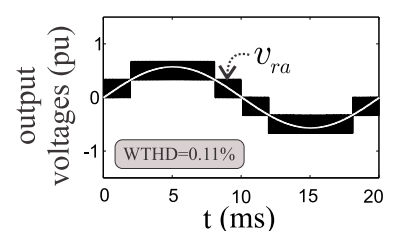

(c)
Fig. 8. Simulation result. Resultant phase-voltages $\left(v_{r j}\right)$. Proposed topologies operate with 2 stages. (a) Conventional $\mathrm{HB}$ with 1 stage. (b) Proposed configuration $K$ in which $N_{1}=N_{2}=1$. (c) Proposed Configuration $K$ in which $N_{1}=1$ and $N_{2}=2$.

BNC connectors with coaxial cables interface. An overview of the experimental setup can be observed at Fig. 9.

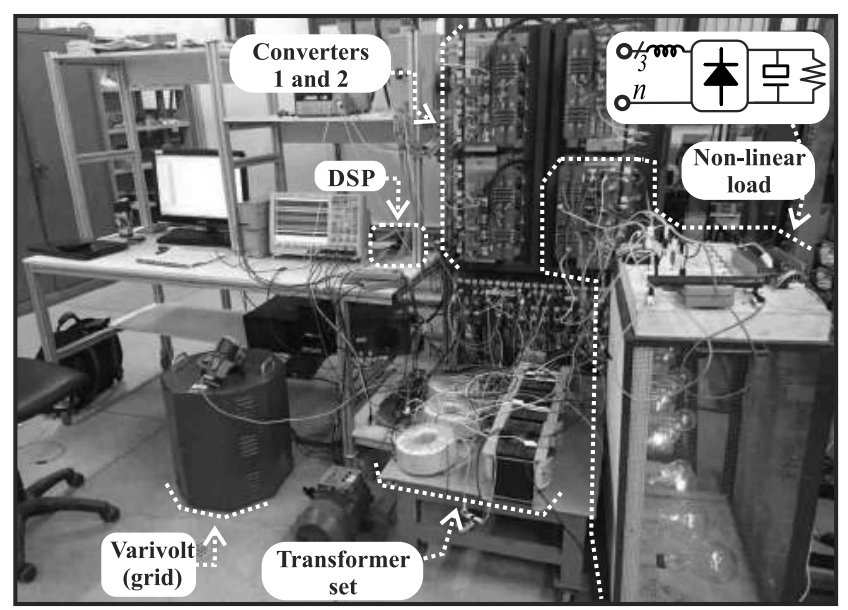

Fig. 9. Photo of the experimental setup.

The PWM algorithm implementation has been tested experimentally. In this case the SAPF converters compensate for reactive power. The results can be seen at Fig. 10 in which the PWM signals and their average values are presented for a set of proposed SAPF configurations operating with 2 stages (i.e., $K=2$ and $N_{1}=N_{2}=1$ ) considered for configuration $K$ [see Figs. 10(a) and (b)]. It can be seen that results are in accordance with the simulated results.

The control strategy presented previously was considered in the experimental tests together with the PWM strategy in order to evaluate the performance of the system. Such results were obtained for the configuration $K$ operating with 2 stages and transformers turn ratios equal to $N_{1}=N_{2}=1$. A set of these results are shown in Fig. 11. It can be seen that the grid currents $\left(i_{g a}, i_{g b}, i_{g c}\right.$ and $\left.i_{g n}\right)$ are well compensated under an unbalanced and non-linear load, see Figs. 11(a)-(c). In fact, the magnitude of neutral grid current $\left(i_{g n}\right)$ is virtually compensated to zero amps. The dc-link voltage regulation was implemented as observed in Fig. 11(d). In this case the amplitude rating of the grid voltage was considered as $E_{g}^{r m s}=50 \mathrm{~V}$. The resultant output voltage $v_{r a}$ generated for harmonic compensation can be observed in Fig. 11(e) in which Figs. 11(f) shows its fundamental signal. The spectral distribution of the load current and grid current at phase $a$ can be observed at Fig. 11(h). Then, the system control has been responsible to the harmonic compensation and has presented a reduction close to $62 \%$ at the THD.

The configuration $K$ with 2 stages (i.e., $\mathrm{K}=2$ and $N_{1}=$ $\left.N_{2}=1\right)$ was tested under a load transient application. The result can be observed at Fig. 12. The control strategy have a satisfactorily performance as it can be seen by means of the dc-link voltage regulation and the grid currents control.

\section{CONCLUSIONS}

This paper has presented an alternative breed of shunt active power filter applied in three-phase four wire systems. From the particular cases considered in this version (i.e., cases with 1 and 2 stages), it can be observed that proposed SAPFs (especially configuration $K$ ) presents the good performance to compensate reactive power, unbalanced loads and harmonic currents provided from non-linear loads. All of these compensations are guaranteed with a reduced harmonic distortion content from the resultant PWM converters. Compared to the conventional configuration with HB [15], the proposed configuration 0 has the same number of IGBTs but has better WTHD values if different transformer turn ratios are

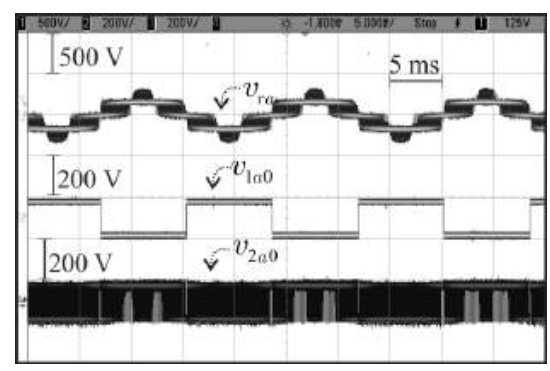

(a)

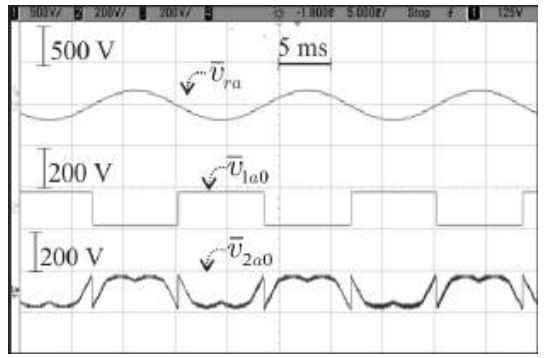

(b)

Fig. 10. Experimental results. (a) PWM signals. (b) Average signals. Set of results for proposed SAPF configuration $K$ with 2 stages (i.e., $K=2$ ) and equal transformer turns ratio (i.e., $N_{1}=N_{2}=1$ ). 


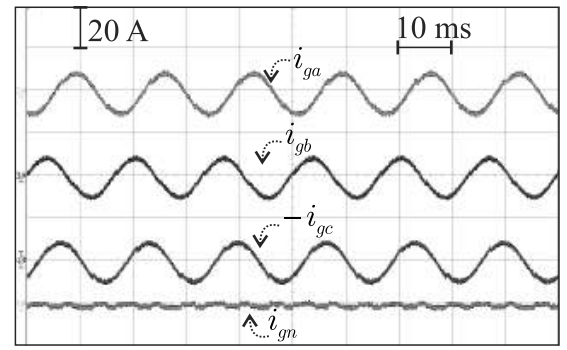

(a)

$\frac{\sqrt{*} v_{C}}{\underline{v}} \frac{100 \mathrm{~V}}{v_{C}^{*}=100 \mathrm{~V}}$

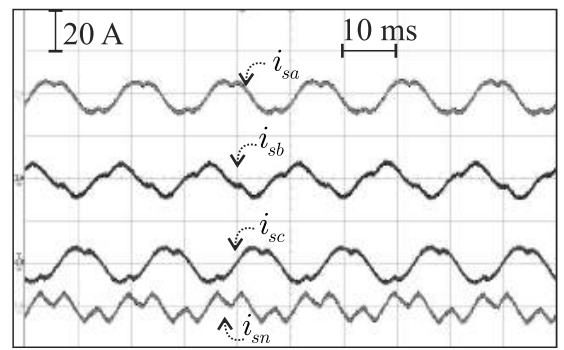

(b)

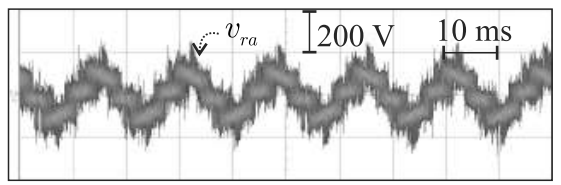

(e)

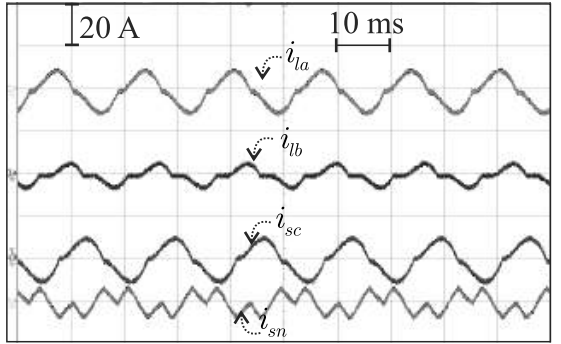

(c)

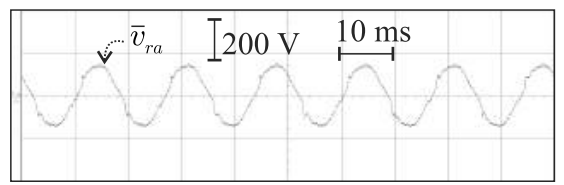

(f)

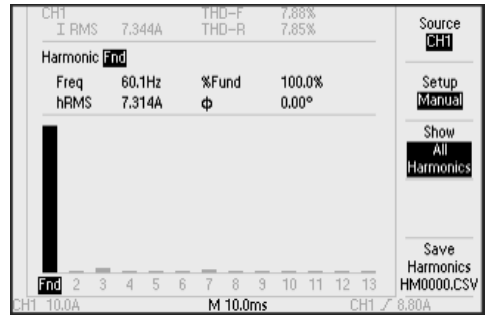

(g)

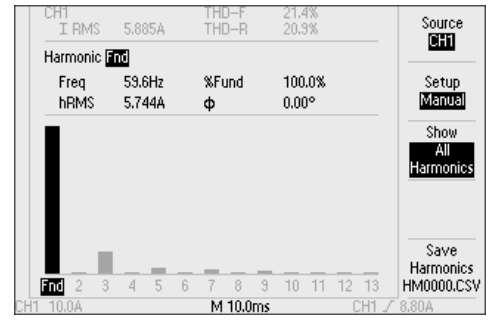

(h)

Fig. 11. Experimental results. Steady stage system currents considered for configuration $K$ operating with 2 stages in which $N_{1}=N_{2}=1$. (a) Grid currents. (b) SAPF currents. (c) Load currents. (d) Dc-link voltage. (e) Resultant output voltage $v_{r a}$ during the compensation. (f) Average signal of resultant output voltage $\bar{v}_{r a} .(\mathrm{g})$ spectrum of $i_{g a}$. (h) spectrum of $i_{l a}$

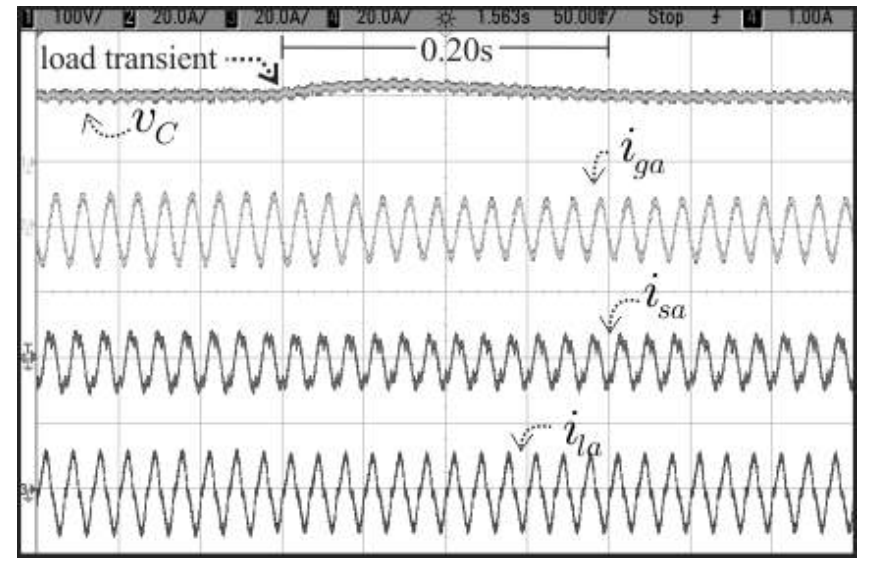

Fig. 12. Experimental results. System performance under a load transient. $N_{1}=N_{2}=1$. (a) Config. $0\left(v_{C}^{*}=115 \mathrm{~V}\right)$. (b) Config. $1\left(v_{C}^{*}=100 \mathrm{~V}\right)$. (c) Config. $K\left(v_{C}^{*}=100 \mathrm{~V}\right)$.

considered. Configuration $K$ presents a higher number of IGBTs. However, it would have the same number of IGBTs if compared to an arrangement of NPC based SAPF [7]. On the other hand, it will have no problems with imbalance at the dc-links [8]. Issues related to dc-link voltage control can be observed for proposed configuration 0 for some points of operations, but the configuration $K$ is not affected by this type of issue. It is worth noting that the number of levels generated at $v_{r j}^{\prime}$ for proposed configuration 0 are equal or higher when compared to the conventional with HB one [15] considering same number of power switches. Some comparison addressing harmonic distortion generated by the resultant converter permits to conclude a better quality at the output voltage waveforms leading in a reduced harmonic content distribution to the grid current. Simulation and experimental results have been present to validate the theoretical approaches and verify the system feasibility.

\section{ACKNOWLEDGMENT}

The authors would like to thank COPELE, CAPES, CNPq and FAPEAL for the financial support and research grants.

\section{REFERENCES}

[1] H. Akagi. New trends in active filters for power conditioning. Industry Applications, IEEE Transactions on, 32(6):1312-1322, Nov 1996.

[2] P. Jintakosonwit, H. Fujita, H. Akagi, and S. Ogasawara. Implementation and performance of cooperative control of shunt active filters for harmonic damping throughout a power distribution system. Industry Applications, IEEE Transactions on, 39(2):556-564, Mar 2003. 
[3] Bhim Singh, K. Al-Haddad, and A. Chandra. A review of active filters for power quality improvement. Industrial Electronics, IEEE Transactions on, 46(5):960-971, Oct 1999.

[4] R. R. Sawant and M. C. Chandorkar. A multifunctional four-leg gridconnected compensator. IEEE Transactions on Industry Applications, 45(1):249-259, Jan 2009.

[5] L.B. Garcia Campanhol, S.A. Oliveira da Silva, and A. Goedtel. Application of shunt active power filter for harmonic reduction and reactive power compensation in three-phase four-wire systems. Power Electronics, IET, 7(11):2825-2836, 2014.

[6] H. Rudnick, J. Dixon, and L. Moran. Delivering clean and pure power. Power and Energy Magazine, IEEE, 1(5):32-40, Sep 2003.

[7] O. Vodyakho and C. C. Mi. Three-level inverter-based shunt active power filter in three-phase three-wire and four-wire systems. IEEE Transactions on Power Electronics, 24(5):1350-1363, May 2009.

[8] S. Kouro, M. Malinowski, K. Gopakumar, J. Pou, L.G. Franquelo, Bin $\mathrm{Wu}$, J. Rodriguez, M.A. Perez, and J.I. Leon. Recent advances and industrial applications of multilevel converters. Industrial Electronics, IEEE Transactions on, 57(8):2553-2580, Aug 2010.

[9] Jih-Sheng Lai and Fang Zheng Peng. Multilevel converters-a new breed of power converters. Industry Applications, IEEE Transactions on, 32(3):509-517, May 1996.

[10] Li Zhang, M.J. Waite, and B. Chong. Three-phase four-leg flyingcapacitor multi-level inverter-based active power filter for unbalanced current operation. Power Electronics, IET, 6(1):153-163, Jan 2013.

[11] K. Antoniewicz, M. Jasinski, M. P. Kazmierkowski, and M. Malinowski. Model predictive control for three-level four-leg flying capacitor converter operating as shunt active power filter. IEEE Transactions on Industrial Electronics, 63(8):5255-5262, Aug 2016.

[12] Xing-Si Pu, Thanh Hai Nguyen, Dong-Choon Lee, Kyo-Beum Lee, and Jang-Mok Kim. Fault diagnosis of dc-link capacitors in threephase ac/dc pwm converters by online estimation of equivalent series resistance. Industrial Electronics, IEEE Transactions on, 60(9):41184127, Sept 2013.

[13] Huai Wang and F. Blaabjerg. Reliability of capacitors for dc-link applications in power electronic converters - an overview. Industry Applications, IEEE Transactions on, 50(5):3569-3578, Sept 2014.

[14] Huai Wang, M. Liserre, and F. Blaabjerg. Toward reliable power electronics: Challenges, design tools, and opportunities. Industrial Electronics Magazine, IEEE, 7(2):17-26, June 2013.

[15] M.E. Ortuzar, R.E. Carmi, J.W. Dixon, and L. Moran. Voltage-source active power filter based on multilevel converter and ultracapacitor dc link. Industrial Electronics, IEEE Transactions on, 53(2):477-485, April 2006.

[16] R. Ghosh and G. Narayanan. Control of three-phase, four-wire pwm rectifier. IEEE Transactions on Power Electronics, 23(1):96-106, Jan 2008.

[17] G. Carlos, C. Jacobina, J.P Mello, and E. Dos Santos. Shunt active power filter based on cascaded transformers coupled with three-phase bridge converters. In Applied Power Electronics Conference and Exposition (APEC), pages 291-297, Mar 2016.

[18] J.I. Leon, R. Portillo, S. Vazquez, J.J. Padilla, L.G. Franquelo, and J.M. Carrasco. Simple unified approach to develop a time-domain modulation strategy for single-phase multilevel converters. Industrial Electronics, IEEE Transactions on, 55(9):3239-3248, Sept 2008.

[19] G.A. de Almeida Carlos and C.B. Jacobina. Series compensator based on cascaded transformers coupled with three-phase bridge converters. In Energy Conversion Congress and Exposition (ECCE), 2015 IEEE, pages 3414-3421, Sept 2015.

[20] P. Verdelho and G. D. Marques. Four-wire current-regulated pwm voltage converter. IEEE Transactions on Industrial Electronics, 45(5):761770 , Oct 1998.

[21] R. M. Santos Filho, P. F. Seixas, P. C. Cortizo, L. A. B. Torres, and A. F. Souza. Comparison of three single-phase pll algorithms for ups applications. IEEE Transactions on Industrial Electronics, 55(8):29232932, Aug 2008.

[22] C. B. Jacobina, M. B. d. Correa, T. M. Oliveiro, A. M. N. Lima, and E. R. C. da Silva. Current control of unbalanced electrical systems. IEEE Transactions on Industrial Electronics, 48(3):517-525, Jun 2001 